Dicenda. Cuadernos de Filología Hispánica

ISSN: 0212-2952

http://dx.doi.org/10.5209/DICE.57707

\title{
De la retórica y poética a la literatura: contexto educativo, disciplinas y manuales en el siglo XIX
}

\author{
Aurora Martínez Ezquerro ${ }^{1}$
}

Resumen. En el convulso siglo XIX se manifiesta un desplazamiento de la retórica y poética a la literatura, esto es, de la aplicación rígida de unas reglas a la ciencia de la comunicación de las ideas que se van vertebrando en un canon de carácter nacional. Esta renovación conceptual surge a la luz de los avances progresistas y sus idearios liberales, que van asentándose en el reinado de Isabel II y que alientan las reformas de los planes de estudios. Mostramos en el presente artículo, y en primer lugar, el contexto político educativo en el que se desarrollan estas transformaciones junto con aspectos que aluden a las disciplinas que nos ocupan, revisamos los conceptos de retórica y poética como ciencias de los manuales de la época y, finalmente, abordamos las conexiones y simbiosis establecidas entre las mismas hasta llegar a la formación de la literatura como teoría que va encontrando su independencia y relevancia.

Palabras clave: Retórica; Poética; Literatura; contexto educativo; siglo XIX.

\section{[en] From rhetoric and poetic to literature: educational context, subjects and textbooks in the $19^{\text {th }}$ century}

\begin{abstract}
In the turbulent nineteenth century a shift in rhetoric and poetic production manifests in literature, that is, the rigid application of rules to science communication of ideas which develop in a canon of national character. This conceptual renewal arises in light of progressive developments and their liberal ideologies, which settle in the reign of Isabel II and encourage reforms in curricula. I will show in this present article the educational policy context in which these transformations are developed together with aspects that refer to the subjects that concern us. I will review the concepts of rhetoric and poetic production as science in the textbooks of that period of time and, finally, I will deal with the connections and established symbiosis between them up to the formation of literature as a theory that is finding its independence and relevance.
\end{abstract}

Keywords: Rhetoric; Poetic; Literature; educational context; nineteenth century.

Sumario: 1. Introducción. 2. Contexto educativo del siglo XIX. 2.1. La educación desde finales del Antiguo Régimen hasta la Ley Moyano. 2.2. De la Ley Moyano a la Primera República (1857-1874). 2.3. La educación en la época de la Restauración hasta fines del siglo XIX. 3. Retórica, poética o literatura preceptiva. 3.1. Entre la razón y el sentimiento. 3.2. Contaminación de disciplinas y profusión de manuales. 4. Conclusiones.

Cómo citar: Martínez Ezquerro, A. (2017). De la retórica y poética a la literatura: contexto educativo, disciplinas y manuales en el siglo XIX, Dicenda. Cuadernos de Filología Hispánica, 35, 185-203.

Universidad de La Rioja

aurora.martinez@unirioja.es 


\section{Introducción}

Los sistemas educativos nacionales surgen en Europa a principios del siglo XIX, concretamente a partir de la Revolución Francesa. En España, la Constitución de 1812 incorpora la idea de la educación como un elemento en cuya organización, financiación y control debe intervenir el Estado, de esta forma se sientan las bases para el establecimiento de nuestro régimen educativo, si bien habrá que esperar a su concreción definitiva, que culmina con la aprobación, en 1857, de la Ley Moyano. Así pues la educación contemporánea nace en nuestro país doctrinalmente unida al Título IX de la Constitución de 1812, a la libertad de enseñanza, a la obligación y gratuidad de Instrucción Pública, a la libertad de imprenta y a la secularización del Estado (Lozano, 1994: 120). La nueva política educativa de las Cortes de Cádiz contribuye a desmantelar el Antiguo Régimen: orden social y educativo ${ }^{2}$ discurren paralelos y se otorga al ciudadano legitimidad y apoyo, que distingue no por el nacimiento sino por la educación recibida.

La legislación educativa -expresión teórica de la ideología liberal- constituye el primer intento de organizar un sistema docente más igualitario. Las normativas ${ }^{3}$ nacidas de ideas de ilustrados y liberales conforman un importante período de reformas que en vano trataría de abortar Fernando VII a su vuelta en 1814. La segunda enseñanza se convirtió en un importante transmisor de los valores del estado liberal y se planteó como etapa de preparación para estudios superiores puesto que los universitarios serían los encargados de dirigir el país. Este potencial provoca que cada gobierno trate de establecer su propia normativa en materia educativa; es más, la lengua y la literatura, debido a su pragmatismo, son consideradas un relevante instrumento de creación de un ideario propio. Se va gestando una nueva concepción de los modelos de enseñanza y surgen cuestiones tan importantes como la reformulación de disciplinas cuyos cánones se mantendrán, por lo general, en posteriores sistemas educativos. Concretamente, la apertura de la retórica -como dominio de la expresión verbal- a otras materias propicia la incorporación de espacios comunes que dará lugar a la moderna concepción de la literatura -como educadora de la sensibilidad, el gusto y la opinión crítica, junto con la creación del canon nacional-.

\section{Contexto educativo del siglo XIX}

\subsection{La educación desde finales del Antiguo Régimen hasta la Ley Moyano}

Los primeros años del siglo XIX (1800-1808) ofrecen en política educativa los últimos intentos reformistas ilustrados cuya expresión legal es el Plan Caballero de 1807 (Delgado, 1994: 41). La invasión del ejército francés, la guerra de la Independencia y los acontecimientos de 1808 originaron una profunda crisis política, financiera y educativa, que abría el camino a cualquier tipo de reforma (Puelles, 1989:

\footnotetext{
Véase J. Álvarez Junco, 2001. En el capítulo XI (533-565) ofrece un apartado dedicado a la educación en este siglo, sus vaivenes legislativos y sus fracasos debidos a la escasez de recursos y a la falta de voluntad política. Véanse M. Á. Galino (1968); M. Utande Igualada (1964 y 1982); A. Viñao Frago (1982); La educación en la España contemporánea (1789-1975), vol. III, en B. Delgado Criado (Coord.) (1994); y MINISTERIO DE EDUCACIÓN Y CIENCIA (1985). Estos estudios abordan con detalle la diversa normativa que durante el siglo XIX reguló la educación en España.
} 
93-133). Es en este año cuando se inicia una nueva etapa en política educativa que se cerrará en 1832-1833 con la abdicación y muerte de Fernando VII.

El reinado de José I, que se extendió desde junio de 1808 hasta el mismo mes de 1813, constituye un período de vacío historiográfico en materia de educación y ciencia. Su política de ámbito educativo estaba basada en los principios que caracterizaron la Revolución Francesa ${ }^{4}$ y que aniquilaron los del Antiguo Régimen. La creación de un sistema educativo público y el desarrollo de la ciencia se intentaron impulsar con la adopción de medidas destinadas a romper con el anterior (Araque, 2009: 2). Con el objetivo de acabar con el absolutismo de la monarquía española y hacer partícipes a los ciudadanos de los derechos conseguidos en la mencionada Revolución, se promulgó la Constitución de Bayona en 1808 que, infortunadamente, no contiene ninguna referencia explícita a la educación ${ }^{5}$.

La Reglamentación de la Instrucción Pública se empezó a concebir a partir de 1810. En espera del anunciado Plan General de Instrucción Pública, se dieron normas para que la enseñanza de las primeras letras y la aritmética siguiese funcionando con normalidad en los edificios de los conventos suprimidos. La Junta de Instrucción Pública -creada en 1811- pretendió dar una estructura uniforme y coordinada a todo el conjunto de medidas educativas; sin embargo, no llegó a concluirse, pero sí se desarrollaron los trabajos de su elaboración a lo largo de 1810. Tenemos noticias de ellos por un informe de Vargas y Ponce que permite conocer algunos aspectos del proyecto (Real Academia de la Historia, 1811: 131, leg. XIII). En las Escuelas Primarias se debía enseñar lectura y escritura, las reglas usuales de aritmética y los primeros conocimientos agrarios (programa que se asemejaba al propuesto por Condorcet en su Rapport). Los Ateneos se debían regir por años escolásticos, y la enseñanza estaba dirigida a hablar la lengua castellana (instrumento vernáculo que van a defender los liberales frente al latín que abanderan los moderados), aprender nociones generales de geografía y de historia universal, principios de las artes mecánicas y aspectos prácticos de comercio y dibujo. El fracaso de la introducción de elementos renovadores -como, por ejemplo, el método Pestalozzi ${ }^{6}$ - abortaron la posibilidad de mejorar la calidad educativa.

Véase M. Delon (1999: 1001-1017), aporta un interesante estudio sobre el triunfo de la elocuencia a finales del siglo XVIII a partir de la impronta cultural francesa de la época.

Durante la Guerra de la Independencia se realizaron aportaciones en materia educativa: se defendió el patrimonio científico, artístico y cultural, y se potenció la educación utilizando edificios y bienes de los conventos suprimidos para la creación de centros públicos. La creación de los Liceos fue importante porque implantaba la segunda enseñanza en España a través de la publicación del decreto de 26 de octubre de 1809 -Jovellanos redactó, en noviembre de 1809, las Bases para la formación de un plan de instrucción pública-. José Martínez de Hervás, marqués de Almenara, como ministro de Interior, promulgó el decreto de 1809, que permitió la creación de casas de educación para las niñas, disponiendo la creación de un colegio femenino en cada provincia, donde se enseñaría Lectura y Escritura, Lengua, Doctrina, Dibujo, Música, Aritmética, Geografía e Historia. La inclusión de estas materias como parte de la instrucción básica supone un gran avance que contribuiría a combatir el alto índice de analfabetismo vigente.

6 Al margen del crédito que pueda darse a Godoy, debe reconocerse que apoyó sinceramente el progreso cultural y científico del país y tuvo en esta actitud uno de los aspectos más positivos de su gestión. Protegió el Instituto de Gijón, la gran empresa de Jovellanos, y su patrocinio fue decisivo para la creación del Colegio de Sordomudos y del Real Instituto Pestalozziano. El método de este pedagogo suizo suponía una transformación radical en relación a los métodos de enseñanza de la época. Sus actividades se inspiraban en el principio formulado por Rousseau que considera al niño como el centro del proceso de aprendizaje (Delgado, 1985: 38-40, vol. III). La práctica se oponía al verbalismo y a la memorización, tan habituales en la enseñanza de la época. Se evitaban los castigos y se consideraba que la escuela era accesible a todos (véase Messer, 1927: 351-363). 
La Comisión de Constitución de las Cortes se ocupó de nuevo de la instrucción pública (Martínez, 2013: 21-22) en octubre de 1813. En su penúltima sesión trató la creación, composición y atribuciones de la Dirección de Estudios, se elaboró un breve proyecto de disposición, que en líneas básicas fue recogido después por el Proyecto de 1814 y el Reglamento de 1821. El Gobierno nombró una Junta para tal tarea ${ }^{7}$, que suscribió en Cádiz -el 9 de septiembre de 1813- un informe para proponer los medios de proceder al arreglo de los diversos ramos de instrucción pública. Este informe ${ }^{8}$, atribuido al poeta y escritor Manuel José Quintana ${ }^{9}$, sirvió de base para elaborar un proyecto de decreto de la enseñanza pública, que fue leído en las Cortes el 17 de abril de aquel mismo año, si bien no llegó a discutirse. El Informe para proponer los medios de proceder al arreglo de los diversos ramos de instrucción pública $^{10}$, elaborado por Quintana en 1814, es una exposición de principios básicos que defiende la instrucción igual, universal, uniforme, pública y libre. Constituye la mejor formulación del ideario liberal en lo que respecta a la educación. En lo que a nuestras materias se refiere, propone reunir en un curso de dos años y con el nombre de Literatura lo que antes se enseñaba separadamente como Retórica y Poética, y el objetivo es adquirir buen gusto en los géneros, valorar la sensibilidad, ofrecer pocos preceptos y muchos ejemplos, y unir a la enseñanza de la literatura la de la historia. Pero el Proyecto de decreto de 1814 no llegó siquiera a debatirse. El 4 de mayo de aquel mismo año se declaraban nulas la Constitución de 1812 y la obra legislativa de las Cortes puesto que se produjo el alzamiento militar liderado por el general Elío, de manera que hubo que regresar al sistema propugnado por el Antiguo Régimen. En febrero de 1815 Fernando VII ${ }^{11}$ nombró una junta que propusiera un nuevo y uniforme plan de estudios ${ }^{12}$.

El pronunciamiento de Riego y el subsiguiente juramento por Fernando VII de la Constitución de 1821 abrieron el trienio liberal (1820-1823). La vuelta a la legalidad supuso el restablecimiento provisional del Plan Caballero de 1807 y el inmediato inicio del proceso de aprobación de un nuevo y completo plan de instrucción pública a partir del no debatido Proyecto de 1814. Reelaborado por la Comisión de instrucción pública de las Cortes, fue debatido y posteriormente aprobado por decreto de 29 de junio de 1821, con el título de Reglamento General de Instrucción Pública, que reproducía sin variaciones el de 1814. Este documento dio carácter legal a una estructura del sistema educativo dividida en primera, segunda y tercera enseñanza,

Formada por Martín González de las Navas, José Vargas y Ponce, Ramón de la Cuadra, Eugenio Tapia, Diego Clemencín y Manuel José Quintana (MINISTERIO DE EDUCACIÓN Y CIENCIA, 1985: 44, vol. III).

8 Se hallaba influido por las concepciones de la Revolución Francesa, concretamente por el Rapport et projet de decret sur l'organisation générale de l'instruction publique, presentado por Condorcet a la Asamblea Nacional de Francia en 1792.

9 Manuel José Quintana (1777-1857) cursó estudios literarios y jurídicos en Salamanca. Aparte de la abogacía, se orienta hacia actividades literarias, poéticas, teatrales y periodísticas. Se integra en el partido liberal y en 1821 es nombrado presidente de la Dirección General de Estudios (Walde, 1994: 235-244).

10 Véase el texto completo en MINISTERIO DE EDUCACIÓN Y CIENCIA (1985: 377-417, vol. I).

11 Véase el artículo de J. de Dios Martín (1987-1988: 187-200), ofrece un interesante estudio sobre un plan de educación sevillano enmarcado en el período en el que Fernando VII provoca la anulación del planteamiento político liberal en favor de opciones absolutistas que suponen un gran retroceso y la vuelta de la educación a manos eclesiásticas.

12 Durante su existencia, hasta 1820, la junta dedicó su esfuerzo a restablecer los colegios mayores y a ordenar visitas a las universidades, a cargo de clérigos absolutistas, con el fin de limpiar y purificar ideológicamente dichas instituciones. 
que no existía en el Antiguo Régimen. De igual modo, sancionaba la división de la instrucción en pública y privada, y determinaba la gratuidad de la enseñanza pública. Asimismo, los escolares tenían que cursar dos años de Literatura y uno de Gramática Castellana, y separadamente Latín ${ }^{13}$.

En 1823 se restablece el poder absoluto de Fernando VII gracias a la intervención de las tropas francesas. Durante los diez años que dura esta época, la reacción absolutista deroga el Reglamento General de Instrucción Pública de 1821 y promulga el Plan literario de estudios y arreglo general de las universidades del Reino (1824), el Plan y Reglamento de escuelas de primeras letras del Reino (1825) y el Reglamento general de las escuelas de latinidad y colegios de humanidades (1826). Estas reformas, que se denominaron Plan de Calomarde -el responsable de su elaboración fue Francisco Tadeo de Calomarde-, supusieron un claro intento de hacer de la instrucción pública un instrumento eficaz en manos del poder dominante (Díaz y Moratalla, 2008: 259).

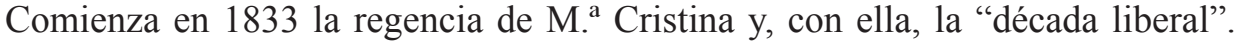
Se constituye el partido moderado cuya ala izquierda dará lugar, en 1837, al nacimiento del partido progresista ${ }^{14}$. Son diez años que definen las dos tendencias liberales: moderados y progresistas. Estos últimos lograrán afianzar sus ideas y su poder (desamortización, supresión de señoríos y órdenes religiosas, y secularización de la enseñanza, entre otras acciones). En 1836 se aprueba el Plan General de Instrucción Pública (llamado Plan del Duque de Rivas) que, si bien apenas tuvo vigencia, supuso un antecedente de la Ley Moyano de 1857. El Plan del Duque de Rivas se centró en la regulación de los tres grados de enseñanza, que ya había comenzado a definir Quintana: la instrucción primaria -que comprende la primaria elemental y la superior-, la instrucción secundaria -dividida en elemental y superior-, y la instrucción superior. En la instrucción primaria no se recoge la materia de Literatura; sí, en la secundaria elemental (Literatura Española) y solo en los "Estudios de erudición" aparece la rama de bibliografía. No obstante, tal y como indica Pedrazuela (2001: 333), "una cosa era lo que los legisladores decidían y otra distinta lo que sucedía en las aulas". Los manuales de la primera mitad de siglo se centraban en aspectos de retórica y poética principalmente (se incluían definiciones de figuras y de modelos latinos para imitar, y se acompañaban de fragmentos de autores grecolatinos) y el canon literario nacional buscaba autores o personajes que fueran modelo de elegancia, mesura, transmisión de valores morales... (el Cid, Fernán González, el marqués de Santillana, Garcilaso, Herrera, Quintana, Jovellanos, Moratín...).

En 1843, cuando Isabel II alcanza la mayoría de edad, comienza un nuevo período en nuestra historia que durará hasta 1854: la "década moderada". La ley clave de esta etapa, de marcado carácter liberal moderado, es la Constitución de 1845. En el ámbito educativo se aprueba por Real Decreto de 17 de septiembre de 1845 el Plan General de Estudios (o Plan Pidal) en el que se renuncia a una educación universal

13 No tuvo casi vigencia efectiva por varias razones: los liberales estaban divididos, además el monarca tenía concedido por la Constitución un derecho de veto legislativo y era previsible que cuando se lo permitieran las circunstancias exteriores (Santa Alianza) o interiores (grupos armados realistas, con apoyo de campesinos y jornaleros opuestos a las reformas desamortizadoras en provecho de la burguesía urbana y los grandes propietarios agrícolas) todo volvería a la situación anterior (Delgado, 1994: 50-51, vol. III).

14 Tras la aprobación de la Constitución de 1837 hubo intentos de desarrollar normativamente los preceptos constitucionales (la Ley de 1838, aprobó uno de los proyectos del Marqués de Someruelos, que regulaba la instrucción primaria), pero la sublevación de Espartero imposibilitó su aplicación. 
y gratuita en todos los grados y se establecen las bases para la primera definición del sistema educativo contemporáneo. Fue redactado por los oficiales de sección de Instrucción Pública, Gil de Zárate (1855: vol. II), Revilla y Guillén.

El Plan Pidal, a pesar de las sucesivas reformas que sufre, llegará a verse recogido en la Ley Moyano en 1857 (MINISTERIO DE EDUCACIÓN Y CIENCIA, 1985: 33, vol. II). Para Romero Tobar (2006: 137), un momento decisivo en la evolución de la nuestra historia lo ofrece esta reforma que establecía como materia obligatoria la Historia Literaria. Los libros de texto -elaborados desde perspectivas teórico-preceptistas e históricas a partes iguales- iban a ser el habitual instrumento de trabajo en la práctica de la Enseñanza Media y de la Universidad. Este hecho origina una copiosa producción bibliográfica que va creando un sentido del rigor científico y de la exigencia estético-crítica; así en muchas preceptivas (González, 2005) se incluyen notas de Historia Literaria. En este sentido, el modelo ${ }^{15}$ de Antonio Gil de Zárate fue una inestimable referencia, como se precisará más adelante.

\subsection{De la Ley Moyano a la Primera República (1857-1874)}

La Ley de Instrucción Pública de 9 de septiembre de 1857 -denominada Ley Moyano por ser Claudio Moyano Ministro de Fomento en el momento de su aprobaciónfue fruto del consenso entre progresistas y moderados, y supuso la consolidación definitiva del sistema educativo liberal así como el comienzo de la estabilidad del desarrollo de la instrucción pública. No fue una ley innovadora, sino una norma que venía a consagrar un sistema educativo cuyas bases fundamentales se encontraban ya en el Reglamento de 1821, en el Plan del Duque de Rivas de 1836 y en el Plan Pidal de 1845.

La Ley Moyano constaba de cuatro secciones (Díaz y Moratalla, 2008: 266). La primera, «De los estudios», regulaba los niveles educativos: primera enseñanza, dividida en elemental (obligatoria y gratuita para quien no pudiera costearla) y superior; segunda enseñanza, que comprende seis años de estudios generales (en el segundo período se incluía la asignatura Retórica y Poética) y estudios de aplicación a las profesiones industriales; $y$, en el nivel superior, los estudios de las facultades (la de Filosofía y Letras incluía Literatura General y Literatura Española, entre otras literaturas), las enseñanzas superiores y las enseñanzas profesionales ${ }^{16}$.

15 No obstante, el plan fue objeto de críticas desde la facción conservadora y por parte de los eclesiásticos. Jaime Balmes fue el más conocido detractor, arremetía sobre todo contra las restricciones y requisitos exigidos a la enseñanza privada, el no reconocimiento de los seminarios como centros de enseñanza secundaria y el monopolio estatal universitario. Su relevancia estriba en el intento de consumación de la secularización de la enseñanza en España y la reforma pedagógica se basaba justamente en este objetivo.

16 En la segunda sección, "De los establecimientos de enseñanza", se regulaban los centros de enseñanza públicos y privados. La tercera, "Del profesorado público", atendía a la formación inicial, forma de acceso y cuerpos del profesorado de la enseñanza pública. Por último, en la sección "Del gobierno y administración de la instrucción pública" se establecían tres niveles de administración educativa (central, provincial y local) perfectamente jerarquizados, y se regulaban unos tímidos intentos de participación de la sociedad en el asesoramiento a las diversas Administraciones. Las características fundamentales de esta ley eran su marcada concepción centralista de la instrucción, su carácter ecléctico y moderado ante la solución de las cuestiones problemáticas (la intervención de la Iglesia en la enseñanza o el peso de los contenidos científicos en la segunda enseñanza), la consolidación de una enseñanza privada -básicamente católica, a nivel primario y secundario- y la incorporación definitiva de estudios técnicos y profesionales a la enseñanza postsecundaria. 
En 1860 se publica en España el Ideal de la Humanidad para la vida, adaptación libre del pensamiento de Krause por Sanz del Río (Krause, 1860). Comienza el nacimiento de una nueva escuela, manifestación española del krausismo, que representó la antítesis del inmovilismo ultraconservador, la concepción liberal del mundo caracterizada por su amor a la libertad de pensamiento, la consideración de la tolerancia como una virtud básica para la convivencia y la fe ilimitada en la educación como factor último de regeneración del hombre (MINISTERIO DE EDUCACIÓN Y CIENCIA, 1985: 40, vol. II). Pero en diciembre de 1864, Pío IX promulgaba la encíclica Quanta cura seguida del Syllabus, ambos documentos condenaban ${ }^{17}$ el mundo moderno influido por la Revolución Francesa y, especialmente, el liberalismo político. La respuesta fue la Real Orden de 27 de octubre de 1864 en la que se insistía en el artículo 170 de la Ley Moyano y el Reglamento de 1859 en relación con el juramento prestado por los profesores en orden a la defensa de la fe, la fidelidad a la Reina y la obediencia a la Constitución.

El 19 de septiembre de 1868 estalla "La Gloriosa"18, comienza el Sexenio Revolucionario y en 1873 es proclamada la Primera República española. Una de las características básicas de este período en el campo de la educación es el impulso de la libertad de enseñanza. El Decreto de 21 de octubre de 1868 defendía el equilibrio entre la educación pública y privada, la necesidad de unos estudios distintos en duración para personas con desiguales capacidades y la libertad de cátedra. Otro importante decreto, aprobado el 25 de octubre de ese año, organizaba la segunda enseñanza, entendiéndola como un complemento o ampliación de la educación primaria, que debía formar ciudadanos ilustrados dotándoles de una amplia instrucción, y regulaba las facultades de Filosofía y Letras, Ciencias, Farmacia, Derecho y Teología ${ }^{19}$. En este contexto la literatura va adquiriendo rango científico, aspecto relevante que se aprecia en los manuales al uso.

\subsection{La educación en la época de la Restauración hasta fines del siglo XIX}

Después de los sucesos del Sexenio Revolucionario, los deseos de paz de amplios sectores de la población facilitaron la llegada de la Restauración. En 1876 se aprueba una nueva Constitución que, siendo marcadamente conservadora, supo conjugar principios de carácter más progresista: el sufragio universal, la declaración de los derechos del hombre y la tolerancia religiosa. La vocación conciliadora de esta ley, sin embargo, no facilitó el consenso en política escolar (MINISTERIO DE EDUCACIÓN Y CIENCIA, 1985: 13, vol. III). Esta dificultad se desprende de la propia interpretación que del articulado constitucional harán los diferentes sectores polí$\operatorname{ticos}^{20}$. El sistema de partidos turnantes hizo de la educación un espacio de lucha

Constituía una llamada a los moderados para evitar la sacrílega enseñanza impartida en la Universidad por profesores liberales y krausistas.

18 El escritor realista Benito Pérez Galdós participó activamente en la vida política y cultural de la época. Véanse C. E. Lida e I. Zavala (1970), J. Casalduero (1974) y G. Cano Jiménez (2011).

19 Aunque no se produjeron grandes innovaciones, muchas de las reformas introducidas en el tema de la libertad de enseñanza se incorporaron al sistema educativo español de modo definitivo; por ejemplo, el artículo 16 del mencionado Decreto indica que los profesores pueden elegir el libro de texto que se halle más en armonía con sus doctrinas y adoptar el método de enseñanza que crean más conveniente (MINISTERIO DE EDUCACIÓN Y CIENCIA, 1985: 334, vol. II).

20 La Constitución, en su artículo 11, reconoce la religión católica como la oficial del Estado, pero a su vez pro- 
política por la libertad de enseñanza, describiendo la legislación educativa un movimiento de péndulo en función de quién ocupase la cartera de Educación. Así, aunque al principio se reafirmó la confesionalidad del Estado, excluyendo la tolerancia religiosa y la libertad de cátedra, más adelante se sucederían momentos en los que se proclama y defiende la libertad de enseñanza y de conciencia. La educación volvió a tener gran protagonismo a finales del siglo XIX. La crisis interna y la independencia de las últimas colonias en Asia y América hicieron que se acuñase la famosa frase de «Salvar a España por la escuela». La regeneración de España pasaba por la reforma educativa. Fruto de este sentimiento será el período de cambios ${ }^{21}$ producido a principios del siglo XX en el que, una vez más, el consenso entre progresistas y liberales volvería a dar sus frutos. Así el Real Decreto de 17 de agosto de 1901, que organizaba los Institutos Generales y Técnicos, establece por primera vez en estos centros estudios que permiten el acceso a la enseñanza universitaria o a las carreras técnicas; es más, en esta normativa se recoge la asignatura Elementos de Historia General de la Literatura en el penúltimo año de los seis que constituyen el grado de bachiller y se le otorga, por tanto, el rango científico que le correspondía.

\section{Retórica, poética o literatura preceptiva}

El siglo XIX ofrece, según se ha indicado, un desplazamiento de la retórica y poética a la literatura, esto es, de la aplicación rígida de unas reglas al establecimiento de una ciencia que, a partir de unos modelos ofrece la posibilidad de comunicar ideas más personales y, con ello, dar cabida al gusto, sentimiento u opinión, tal como se expondrá a continuación. Este cambio conceptual surge en el contexto de los idearios liberales y de sus reformas de los planes educativos.

\subsection{Entre la razón y el sentimiento}

En la obra de los enciclopedistas del siglo XVIII encontramos reivindicaciones de un método racional de acercamiento a la literatura y al arte en general, esta necesidad de un orden razonado del conocimiento de orientación científica se trasladará de forma específica a las bellas letras. En un camino intermedio entre "lo racional y lo sentimental" se halla la Filosofia de la elocuencia de Capmany (1777) -autor influido por la Enciclopedia francesa-, que supone un acercamiento a la teoría literaria española puesto que es concebida como una superación de los preceptos de corte escolástico hacia los principios básicos de la razón y del sentimiento (Aradra, 1997: 137). Será a partir de la traducción y divulgación de las Lecciones sobre la Retórica y las Bellas Letras (1798-1801) de Hugo Blair (1816) cuando se advierta una separación y

clama la libertad de cultos y de conciencia. El sector más intransigente del catolicismo español mantenía que la confesionalidad del Estado implicaba el control ideológico de las escuelas y, por el contrario, las tesis de los liberales más progresistas afirmaban que la tolerancia de cultos y la libertad de conciencia significaban, necesariamente, la libertad de cátedra. El artículo 12 regulaba, de forma incompleta, diversos aspectos de la educación.

21 Se reforman las escuelas normales, la enseñanza secundaria y los planes de estudio de las enseñanzas universitarias. Los cambios también afectan a la reglamentación de los exámenes, a la regulación de la enseñanza de la religión, a la titulación del profesorado, a la reordenación del Bachillerato y a la autonomía universitaria. Un hecho destacado es el intento de que los maestros pasen a ser pagados por el tesoro público, puesto que hasta entonces lo hacían los ayuntamientos y su salario era muy deficiente. 
reformulación más clara de estos presupuestos filosóficos y estéticos. Esta obra no era una poética (González, 2003-2004: 114) sino un texto utilizado oficialmente en España para la enseñanza de las Humanidades que ofrecía una visión generalista del concepto de la Literatura basado en una lógica partitiva entre los géneros en prosa (elocuencia e historia, incluye a las novelas) y las composiciones poéticas, junto con cantos dedicados a la dramática y la epopeya (Soria, 1979: 363-388).

Así Blair, en la lección II que trata sobre el gusto, declara:

Pero aunque la razón pueda dirigirnos algún tiempo en los juicios relativos á las obras de gusto; no debe olvidarse, que las últimas inducciones, á que nos guian nuestros raciocinios, se refieren por último al sentimiento y á la percepción. Podemos observar, y raciocinar acerca de la propiedad de la conducta en una tragedia ó epopeya: los raciocinios exactos sobre este asunto corregirán el capricho de un gusto no ilustrado; y establecerán los principios para juzgar lo que es ó no digno de elogio. Pero al mismo tiempo estos raciocinios apelarán por último al sentimiento. El fundamento en que estriban está en la experiencia, que hay de agradar mas comúnmente al género humano. [...] Por tanto estos dos sistemas se diferencian muy poco en la realidad. En uno y otro entran el sentimiento y la razón: y los dos pueden ser compatibles, siempre que à cada una de estas facultades se dé el lugar correspondiente (Blair, 1816: 40, vol. I).

Las mencionadas Lecciones inauguran la incorporación de una parte de la estética en las obras de teoría literaria ${ }^{22}$. Este fundamento artístico junto con el éxito que tuvieron las teorías sensualistas ${ }^{23}$ del ilustrado escocés contribuyeron en gran medida al cambio de la percepción de estos conceptos. José Luis Munárriz, el traductor de este manual, considera que la superioridad de esta obra "sobre todos los tratados del mismo genero está en las reglas generales, y en los principios del gusto y del raciocinio que tan felizmente ha sustituido à los artificiales de los retóricos escolásticos" (Blair, 1816: XV, vol. I). Por eso, aunque los títulos y los índices de contenidos de los manuales de retórica y poética guardan bastante similitud -todos responden a las directrices señaladas por los planes de estudio vigentes-, constatamos que en muchos casos responden a distintas concepciones ${ }^{24}$ estético-filosóficas que se reflejan en nociones como belleza, gusto o incluso literatura, como se apreciará más adelante.

Comenzaba ya la reforma de la retórica escolástica, impulsada por el debate que se creó acerca de la utilidad de la retórica como reglamentación de la actividad oratoria y literaria en general. Según Aradra (1997: 144), algunos autores -Feijoo ${ }^{25}$ entre ellos- manifiestan de forma clara la inutilidad de las reglas para la creación; esta afirmación favoreció una amplia polémica, incluso se convirtió en un lugar común abordar la necesidad de la retórica o de los estudios literarios. Es más, la tendencia

22 Considera P. Aullón de Haro (1994: 16), salvando las distancias cronológicas si bien no desligadas de las mismas, que "Crítica y Teoría, sobre todo, están en ajustado contacto con la Estética".

23 Véase M. C. García Tejera (1990: 449-457, vol. I), ofrece un panorama general de las diversas doctrinas desarrolladas en España en el ámbito del pensamiento y de la enseñanza.

24 Véase I. Morales Sánchez (2000: 167-175)). Esta autora aborda la problemática surgida en torno a la clasificación y ordenación de la Literatura en géneros en el espacio singular que ofrecen los manuales de retórica y poética en el contexto del siglo XIX; asimismo, ofrece amplia bibliografía sobre la cuestión.

25 Véase B. J. Feijoo (1742-1760). El tema aludido se aborda concretamente en la carta 6. del tomo II, "La elocuencia es Naturaleza y no Arte". 
a la eliminación de las reglas memorísticas -que se desarrolló paralelamente- contó con otra línea reduccionista de la retórica a la elocutio encabezada por Capmany y secundada por Traggia y Madramany en el XVIII. La reorganización a la que se sometieron los estudios retóricos con la implantación de concepciones similares potenciadas por la difusión de las obras de Blair y Batteaux (1797-1805: vol. I) contribuyó a una ampliación del campo de referencia -la persuasión oratoria- de la retórica tradicional; para este la retórica no solo incluye el ámbito de la persuasión, sino que se ocupa de los medios para tratar cualquier asunto de modo elegante y sólido (Aradra, 1997: 145). Tal consideración constituye una apertura hacia lo literario, que se manifestaría en la diferente atención prestada a los componentes de la retórica, en la que destaca el reducido espacio que concede a la invención y a la disposición. La retórica se amplía fuera del ámbito puramente oratorio (la retórica oratoria ya se había extendido a los demás géneros en prosa) y, a la vez, ofrece un conjunto de reglas para hablar y escribir correctamente, es decir, se hace sinónima de teoría del estilo. Nos encontramos, por tanto, ante un panorama muy diverso en relación con la retórica y su ubicación en el estudio de la literatura en el que la elocución va tomando protagonismo y se hace común a todos los géneros literarios.

Fernández López considera que en la España del siglo XIX el legado de la retórica se aprecia de forma especial en el ámbito de las bellas letras, de la literatura y de su enseñanza. La literatura se concibe, siguiendo la tradición neoclásica, como un arte sometido a reglas, y dichas reglas se encuentran en lo que se llama retórica y poética:

Esta Retórica subsumida en la noción más general de literatura extrae del sistema clásico las fases tradicionales de constitución de un texto (inventio, dispositio y elocutio), a menudo sin establecer conexión explícita con la doctrina recepta, y, bajo el nombre de oratoria o elocuencia, considerados géneros de la prosa, suele dar cabida también a una versión muy reducida del género natural de la retórica, el del discurso pronunciado ante un auditorio (Fernández, 2008: 38-39).

Si nos remontamos a la antigüedad clásica, las conexiones entre retórica y poética, o literatura en general, ya se manifestaban tanto en la práctica literaria como en su teorización. Los escritores de retórica, comenzando por Aristóteles (Kennedy, 2003: 158-159), tomaban frecuentemente ejemplos de fuentes literarias para la invención y el estilo, por tanto, el uso de citas de la poesía ha constituido una efectiva técnica retórica. Los progymnásmata o ejercicios previos a la declamación ya se practicaban en las escuelas de retórica. Con el uso creciente de la escritura para la composición en el siglo IV a. C. se aprecia un desplazamiento gradual de la atención de los estudios retóricos del arte oral al arte escrito. Este proceso afecta a la retórica tal como se enseña en las escuelas, se describe en los manuales, y se practica en la composición: nos hallamos ante la literaturización de la retórica o la creación de una literatura retórica.

A partir del Renacimiento sus límites empezaron a confluir: la poética se retorizó y la retórica se literaturizó. La concepción persuasiva del hecho literario es uno de los puntos que enlaza ambas disciplinas, en las que se advierte una relación de continuidad entre la imitación y la persuasión. Para Mortara Garavelli (1991: 54), las poéticas del Romanticismo -que no tolera constricciones del "genio sin normas"- contribuyeron a enterrar las técnicas retóricas y su didáctica bajo un cúmulo de reproches. Se aceptaban las reglas de la gramática como necesarias para el buen funcionamiento 
o uso correcto de la lengua, si bien se negaba toda legitimidad a los cánones de la retórica por considerarlos ataduras para la libertad expresiva. Los románticos pusieron en evidencia las deficiencias de la poética tradicional (Morales, 2000: 169), al tiempo que se iniciaba el largo camino de reestructuración de los estudios literarios. Pero ya se ha indicado que en el siglo XIX se incidía en la importancia de las bellas letras (Núñez y Campos, 2005: 59) -gramática, retórica y poética-, se consideraba que con una sólida formación lingüística y estética se lograba, mediante el uso correcto y bello del lenguaje, la exacta enunciación de los pensamientos. Por tanto, son necesarios principalmente tres aspectos: formación del gusto ${ }^{26}$, conocimiento de las normas que deben guiar el proceso de aprendizaje del estilo y cultivo de la imaginación como facultad central de nuestra actividad (García, 1994: 277-284, vol. I).

\subsection{Contaminación de disciplinas y profusión de manuales}

En la ordenación interna de los tratados -bajo la influencia de los mencionados condicionantes estéticos y filosóficos-, apreciamos la aparición conjunta de retórica y poética como parte nuclear que surge en los últimos estadios del XVIII y se consolida de forma generalizada durante el siglo siguiente. Nos hallamos ante una clara contaminación de ambas disciplinas: lo que en un principio se configura como parte especial, dedicada al análisis de los géneros en prosa y verso, de la retórica y de la poética respectivamente, con los cambios conceptuales operados en el terreno de la literatura alterará su contenido. Adquiere entonces la retórica un carácter teórico general sobre la elocución literaria, mientras que la poética se centra en la teoría de los géneros. Así, la larga convivencia de retórica y poética durante prácticamente todo el siglo XIX acaba resolviéndose en una progresiva contaminación estructural-conceptual (Aradra, 1997: 149).

Los tratados públicos en España se verán influidos por esta división ${ }^{27}$, como es el caso de los Principios de Retórica y Poética (1805), de Sánchez Barbero, o el Arte de hablar en prosa y verso (1826), de Gómez Hermosilla, entre otros. Pero la reorganización en el tratamiento de los géneros se consolidará en España a partir de la mencionada Lecciones sobre la Retórica y las Bellas Letras, de Hugo Blair, en la que tienen cabida los distintos géneros orales y escritos, y tanto en prosa como en verso. Se advierte, especialmente en la primera mitad de siglo, la frecuencia de títulos (Fernández, 2008: 83-98) que plantean el paralelismo entre prosa y verso y retórica y poética, en el terreno incipiente de la literatura que iba apareciendo como superación de ambas distinciones.

El período en que tiene lugar el desplazamiento de la retórica a la implantación de la historia de la literatura es largo, y coexisten las retóricas con el nuevo método descriptivo y valorativo con que las historias juzgan las obras literarias; por otro lado, como coincide con la nueva organización dada por Pidal (Plan Pidal) y Zárate (Núñez y Campos, 2005: 66) en 1845 a los centros de secundaria, durante el mismo se crean las primeras cátedras de Historia de la Literatura y se editan los primeros manuales de dicha asignatura. En las instituciones educativas recién creadas se en-

26 Para el crítico francés Saint-Beuve, el buen gusto es moderación, equilibrio racional y representa el lado subjetivo de lo que considera como tradición y esencia de lo clásico (Wellek, 1972: 83, t. III).

27 La bipartición de la traducción de García de Arrieta de los Principios filosóficos de la Literatura (1797-1805), de Charles Batteux, se aprecia en los cuatro volúmenes que se dedican a la poética, y otros tantos a la retórica. 
tremezclan las enseñanzas normativas de unas con el nuevo método de pensar de las otras.

La demanda que surge a la luz de los cambios promovidos por las diferentes legislaciones y por el reajuste de las disciplinas ofrece numerosas obras destinadas a la enseñanza de la retórica, poética y literatura, con los contornos cada vez más difusos, según se ha mostrado. La organización de los tratados de retórica y poética -receptiva a las transformaciones teóricas que se imponen progresivamente- se resuelve en algunos manuales mencionados en las mismas tres partes (estética, preceptiva e histórica), que consolidan una visión asimismo tripartita e interrelacionada del conocimiento teórico de la literatura. Numerosos son los títulos que muestran el mencionado paralelismo entre prosa y verso y retórica y poética:

Campillo y Correa, Narciso: Retórica y Poética o Literatura preceptiva, Madrid: Librería de Gregorio Hernando, 1875, 2. ${ }^{\mathrm{a}}$ ed.

Camus, Alfredo: Curso elemental de Retórica y Poética, Madrid, Imprenta de la Publicidad, 1847.

Canalejas y Casas, Francisco de Paula: Curso de Literatura General, Madrid, Imprenta La Reforma y M. Minuesa, 1868-1869.

Casas y Gómez de Andino, Hipólito: Retórica y Poética o Literatura preceptiva, Madrid y Valladolid, Imprenta de Gaviria y Zapatero, 1880.

Coll y Vehí, José: Elementos de Literatura, Madrid, M. Rivadeneyra, 1856.

Coll y Vehí, José: Programa de Retórica y Poética, Barcelona, Imprenta del Diario de Barcelona, 1870.

Fernández Espino, José María: Curso de literatura general, Sevilla, Imprenta de J. M. Geofrín, 1847.

Flórez Villamil, Manuel: Lecciones de Retórica y Poética o Literatura Preceptiva, Madrid, Establecimiento Tipográfico de G. Juste, 1900.

Gil de Zárate, Antonio: Manual de Literatura. Principios generales de Poética y Retórica, Madrid, Brix Ediciones, 1842.

Giner de los Ríos, Hermenegildo: Arte literario, o Retórica y Poética. Preceptiva para servir de texto en los Institutos de $2^{a}$ Enseñanza, Madrid, Tipografía Franco-Española, 1891.

Gómez Hermosilla, José: Arte de hablar en prosa y verso, Madrid, Imprenta Real, 1826.

Lista y Aragón, Alberto: Lecciones de literatura española, Madrid, Imprenta de Nicolás Arias, 1836.

Loscertales y Ruata, Mariano: Programa de literatura general preceptiva (retórica y poética), Logroño, Imprenta de Federico Sanz, 1883.

Monlau y Roca, Pedro Felipe: Elementos de Literatura o arte de componer en prosa y verso (para uso de las universidades e institutos), Barcelona, Imprenta de Pablo Riera, 1842.

Monlau y Roca, Pedro Felipe: Elementos de Literatura o Tratado de Retórica y Poética, Madrid, Ribadeneyra, 1856, 2. ${ }^{\mathrm{a}}$ ed.

Mudarra y Párraga, Prudencio: Lecciones de literatura general y literatura española, Sevilla, Imprenta de Gironés y Orduña, 1876.

Muñoz Sanz, Pedro: Compendio de Literatura preceptiva o Retórica y Poética, Palencia, Establecimiento Tipográfico de J. M. de Herrán, 1890.

Ríos, Diego Manuel de los: Instituciones de Retórica y Poética o Elementos de Literatura, Madrid, Imprenta de Manuel López de G. Hoya, 1863.

Sánchez Barbero, Francisco: Principios de Retórica y Poética, Madrid, Imprenta de la Administración del real Arbitrio de Beneficencia, 1805. 
Terradillos, Ángel María: Lecciones elementales de Retórica y Poética o sea Literatura Preceptiva, Madrid, Imprenta y librería de los hijos de Vázquez, 1867, 6. ${ }^{\mathrm{a}}$ ed.

La superproducción de manuales obedece también a que en muchos casos cada profesor de estas materias (tanto en la enseñanza primaria como en la secundaria e incluso en la universitaria) elaboraba su propio libro de texto, deudor en gran medida de textos anteriores que habían gozado de gran prestigio. En algunas de estas obras ya se aprecia que la retórica y la poética constituyen la parte preceptiva de la composición y teoría sobre los géneros literarios. Perdida la orientación oral de la retórica, en el momento en que los principios de la oratoria se extienden a la prosa y esta al campo de la literatura -sobre la que ejercía su hegemonía la poética-, ambas disciplinas se unirán ya de forma inseparable. Kennedy considera que el concepto moderno de

literatura como conjunto de obras publicadas de calidad estética se derivó del término "belles lettres" en el siglo XVII en Francia y en el XVIII en Inglaterra. La retórica puede considerarse anterior a la literatura en el sentido de que el discurso oral precede al uso de la escritura en miles de años (Kennedy, 2003: 157).

Pero ante la confluencia terminológica, enseguida se pronuncian autores que reclamaron un cambio de denominación de la retórica -entendida como estudio de la elocución general- por principios de literatura. El concepto de literatura va recogiendo los parciales contenidos de la retórica y poética como teoría de los géneros (Morales, 2000: 171-173). A partir del último tercio del siglo XIX se hicieron frecuentes las alusiones al rango científico de la literatura y se acentuaron las diferencias entre arte y ciencia, retórica y poética y literatura, territorios fronterizos inmersos en continuas vacilaciones terminológicas, como hemos apreciado en los títulos de los manuales y en las denominaciones de las asignaturas (de retórica y poética a la literatura preceptiva y a la literatura general). La indagación teórica que desde mediados del XIX se registra sobre el estudio de la literatura pronto plantea una delimitación de intereses que permitirá la moderna configuración de estos estudios. Además de la parte preceptiva en sí misma (retórica y poética) y de la reflexión general sobre el hecho literario, la historia de la literatura se empieza a presentar de forma independiente (Rincón, 1993:150-153). La importancia adquirida por los modelos y las propias necesidades docentes propiciará la aparición de antologías ${ }^{28}$ que empiezan a proliferar como complemento a los textos teóricos ${ }^{29}$.

Para Romero Tobar (2006: 138), José Amador de los Ríos fue el primer español que escribió una historia literaria en lengua castellana, Historia crítica de la Literatura Española (1861), obra que se había ilustrado con anotaciones y traducción de una parte de la Historia de Sismondi. Según Mainer (2000, 171), el primer manual de historia de la literatura nacional fue el Manual de Literatura (1842) de Gil de Zárate, resumen de las opiniones comunes que alentaron el armisticio entre progre-

28 En este sentido, el modelo de Gil de Zárate fue seguido por sus coetáneos. La segunda parte de su Manual -Resúmen Histórico de la Literatura Española. Segunda parte del Manual de Literatura (1874)- es una antología de textos comentados que abarca desde sus orígenes hasta el siglo XVIII y se organiza en poesía, escritores dramáticos y prosa.

29 Véase el capítulo de J. A. Hernández Guerrero (1990: 537-544, vol. I), aborda los fundamentos y métodos de las retóricas y poéticas españolas del siglo XIX. 
sismo histórico y encanto estético. Esta obra ofrece pasos muy significativos en la separación de preceptiva e historia. Zárate (Núñez, 2014: 42) pone de manifiesto, por un lado, la necesidad de educar literariamente a los jóvenes mediante el conocimiento de poetas y prosistas que les valgan como modelos y el aprendizaje de las reglas y convenciones de lo literario; y, por otro lado, considera que estos estudiantes habrían de distinguir las cualidades de dicha literatura que conforman el espíritu de la nacionalidad española. Este modelo historicista con raíces románticas impregnó el moderno sistema educativo y contribuyó a la formación de la conciencia nacional (Pedrazuela, 2001: 350-351) de los estudiantes. Este volumen se divide en seis secciones: reglas comunes para todos los escritos, reglas particulares de los escritos en verso, principios filosóficos comunes a todas las composiciones literarias, reglas particulares de las composiciones en prosa, reglas particulares de las composiciones en verso y composiciones dramáticas. En su prólogo se recogen las siguientes palabras:

Fácil nos hubiera sido dar en pocas páginas los nombres y definiciones de las figuras retóricas, de las partes de un discurso, y de las diferentes composiciones en prosa y verso; pero opinamos que poco se consigue cargando la memoria de los principiantes con semejantes cosas, si no se les enseña al propio tiempo a discurrir [...] por esta razón [...] nos detenemos algo en los que creemos más importantes, ya porque encierran principios sobre los cuales conviene fijar la atención, ya porque dan á conocer mejor la índole de nuestra literatura. Esta última consideración nos ha hecho añadir la segunda parte que se reduce á un resúmen breve, pero crítico y razonado de nuestra historia literaria. [Ofrecemos] los principios y reglas generales para la composición; y una guía que les conduzca por el inmenso campo de nuestra Literatura, para saberla apreciar suficientemente, y conocer lo que deben huir o estudiar en ella (Gil de Zárate, 1844: 4).

La incorporación de la estética a los tratados de retórica ${ }^{30}$ y de la influencia de la filosofía en la configuración general de los textos resalta la importancia de esta parte no solo por la estructura, sino también por las ideas. Los autores son conscientes del valor de este nuevo enfoque en los estudios literarios y enfatizan el papel determinante de la estética en la moderna ciencia de la literatura. Así lo demuestra el riojano Hipólito Casas y Gómez de Andino ${ }^{31}$ (1880), quien aboga por la necesaria incorporación de nociones de Lógica, Gramática, Estética y Teoría de la producción literaria a las obras de enseñanza. Su conocido manual, Retórica y Poética o Literatura preceptiva (1880) tuvo muy buena acogida en la prensa de la época y en los centros de enseñanza puesto que pronto se adoptó como libro de texto en muchas cátedras. Pese a su brevedad, el autor se muestra convencido de la importancia que tiene denominar a la asignatura Literatura Preceptiva. Así lo justifica en su segunda edición, de 1882:

\footnotetext{
A. López Eire aborda el concepto de retórica clásica y sus aplicaciones en la actualidad (1998 y 2000).

31 Este autor nació en Santo Domingo de La Calzada (La Rioja), el 13 de agosto de 1848, y murió en Zaragoza, el 7 de noviembre de 1916. Fue Licenciado en Filosofía y Letras, Catedrático de Retórica en el Instituto de León, Rector de las Universidades de Zaragoza y de Orense, Gobernador Civil de Alicante, Tarragona y Valladolid, Caballero de la Gran Cruz de Isabel la Católica, Hijo Predilecto de Santo Domingo de La Calzada, Académico de Bellas Artes de San Luis y Medalla de Oro de los Sitios de Zaragoza. Publicó sus primeros versos en el semanario logroñés El Sábado (VV. AA., 1995: 39-40).
} 
Nuestra asignatura se conoce históricamente con el nombre de Retórica y Poética, título que no responde al verdadero y acabado concepto de la misma [...]. Más propio sería titular nuestra enseñanza con el nombre de Literatura Preceptiva, nombre que precisa y completa su verdadero contenido, según se desprende del concepto que vamos a exponer (Casas y Gómez de Andino, 1882: 10-11).

El esquema general del tratado responde a una bipartición: en primer lugar, aborda los elementos de la obra literaria (pensamientos, lenguaje y belleza) y la teoría de la producción literaria (artista, obra y público), en la segunda parte expone los géneros literarios (poético, oratorio y didáctico), y concluye con un apéndice de la Epístola de Quinto Horacio Flaco a los Pisones, en latín. Parte del interés de este manual reside en la perfecta síntesis de los elementos que aborda (Martínez, 2014: 197-212).

Tanto en este tratado como en otros de la época se aprecia la escisión de las disciplinas a favor de la relevancia que cobra la literatura. La independencia de esta ciencia constituye un logro porque permite que el gusto y la sensibilidad sean educados a la par que fomenta el juicio del aprendiz, que ya no se halla sometido a unas inflexibles reglas que debe acatar como parte del conocimiento de las "bellas letras".

\section{Conclusiones}

A finales del siglo XVIII y durante el XIX prolifera una nueva concepción de los modelos de enseñanza y surge la reformulación de disciplinas que sentarán cánones mantenidos posteriormente. Como parte del movimiento romántico de la literatura, se produjo una reacción en contra de la naturaleza tan estructurada de la retórica de manual, con sus reglas de argumentación, de disposición y de estilo. Esta disciplina fue perdiendo paulatinamente su primacía en el sistema educativo, si bien se intentó conciliar la línea más tradicional con otras más novedosas en una evolución que toma relieve merced a las influencias que suponen las ideas románticas. Este desplazamiento de materias se produce en un momento político e histórico muy peculiar que nace con la anómala situación de las Cortes de Cádiz -aisladas del resto del país-, esto es, a la luz de la primera expresión ideológica y legal del liberalismo español. La política educativa de las Cortes gaditanas fue una medida más que contribuyó a desmantelar el Antiguo Régimen e instaurar un nuevo tipo de relaciones y dio el impulso necesario para el asentamiento de nuestra educación. La legislación de la enseñanza constituye, por tanto, la primera expresión teórica de esta ideología liberal, si bien coexistían posiciones contrapuestas.

En el primer cuarto de siglo las nuevas concepciones ya comenzaban a introducirse. La legislación educativa fue marcando el camino que conduciría a un modelo más perfilado de las ideas liberales en este ámbito, y así se aprecia en el Plan General de Estudios de 1845 (Plan Pidal) o en la Ley de Instrucción Pública de 1857 (Ley Moyano). El modelo de educación literaria basado en la retórica estuvo vigente hasta el momento en que tiene lugar la implantación del sistema escolar moderno -hacia 1845, y gracias a él se introduce en las aulas una nueva forma de entender lo literario que inician las historias de la literatura -necesarias, a su vez, a las burguesías-.

La apertura de la retórica a otras materias propicia la incorporación de espacios comunes que dan lugar a la moderna concepción de la teoría de la literatura. La dis- 
tinción schegeliana establecida entre los conceptos romántico y clásico se aprecia en los tratados que lo aplican a distintas manifestaciones artísticas originadas desde diferentes valoraciones de la literatura, y en algunos autores subyace la conciencia historicista que contribuirá a la nueva concepción del hecho literario como imposible de circunscribirse a criterios fijos. La preceptiva decimonónica marca, por tanto, la crisis del sistema clasicista. La educación liberal que emanaba de la normativa en educación asumía la herencia del pensamiento ilustrado, las aportaciones procedentes del utilitarismo moral anglosajón, la influencia del romanticismo literario y la impronta francesa, todo ello en un contexto histórico marcado por tensiones y oposiciones entre tradicionalismo y liberalismo, entre reaccionarios y afrancesados. Así pues motivos políticos, socioculturales, pedagógicos, lingüísticos o artísticos propician que el modelo retórico sea sustituido por el historicista.

La larga convivencia de retórica y poética durante prácticamente todo el siglo XIX acaba resolviéndose, según se ha indicado, en una progresiva contaminación estructural-conceptual. El canon retórico consistió básicamente, y hasta mediados del siglo XIX aproximadamente, en el aprendizaje de las reglas del buen decir y de los principios que habrían de guiar a los escolares para componer obras literarias; y a la vez, en la consagración y canonización de los clásicos grecolatinos como ejemplos de imitación para escribir o hablar bien. Pero las historias de la literatura van desplazando a las retóricas y se convierten en el centro de la educación literaria abriendo nuevas vías para la interpretación y el análisis de las obras. Coexistiendo con los aprendizajes retóricos, se va abriendo camino la visión positivista de la literatura que permite la investigación de las fuentes, el estudio de los textos, la edición crítica de obras, el conocimiento de la biografía de los autores y la concepción de la obra como expresión del creador y como documento histórico que representa el espíritu de la época a la que pertenece.

Esta perspectiva historicista de la literatura no se halla tan lejos del actual magisterio que se practica en el apartado literario de la asignatura denominada Lengua Castellana y Literatura de nuestra Educación Secundaria. Se mantiene el interés por el estudio de ciertas épocas y autores ${ }^{32}$ en detrimento de otros escritores que también dejaron su impronta en la historia de nuestra literatura, pero la cuestión del canon literario no ocupa, de momento, el tema central del presente estudio, si bien debía ser mencionado.

\section{Obras citadas}

Álvarez Junco, José: Mater dolorosa. La idea de España en el siglo XIX, Madrid, Taurus, 2001.

Aradra Sánchez, Rosa María: De la retórica a la teoría de la literatura (siglos XVIII y XIX), Murcia, Universidad de Murcia, 1997.

Araque, Natividad: "La educación en la Constitución de 1812: antecedentes y consecuencias", Revista de la Facultad de Ciencias Sociales y Jurídicas de Elche, I (2009), pp. 1-21.

32 Núñez (2016: 100-109) ofrece un interesante estudio sobre la configuración del canon clásico, entendida como un complejo proceso histórico en el que intervienen factores de diversa índole que tienen que ver con la Estética, con la constitución de las disciplinas, con la organización del currículum y, por tanto, con el papel que juegan la literatura y las humanidades en las sociedades modernas. 
Aullón de Haro, Pedro: "Epistemología de la teoría y la crítica de la literatura”, en Pedro Aullón de Haro (coord.), Teoría de la crítica literaria, Trotta, Madrid, 1994, pp. 1126.

Batteaux, Charles: Principios filosóficos de la literatura, o Curso razonado de bellas letras y de bellas artes. Obra escrita en francés por el señor abate Batteux (traducción de García de Arrieta), Madrid, Sancha, 1797-1805, 9 vols.

Blair, Hugo: Lecciones sobre la retórica y las bellas letras (Las tradujo del inglés Don José Luis Munárriz), Madrid, Ibarra, 1816, 3. . ed., 4 vols.

Cano Jiménez, Gema: "La de Bringas: una revisión de La Gloriosa dieciséis años después”, Espéculo: Revista de Estudios Literarios, 48 (2011). Edición digital: http://www.ucm.es/ info/especulo/numero48/bringas.html. [Consulta: 29 de enero de 2015).

Casalduero, Joaquín: Vida y obra de Galdós (1843-1920), Madrid, Gredos, 1974.

Casas y Gómez de Andino, Hipólito: Retórica y Poética o Literatura preceptiva, Madrid y Valladolid, Imprenta de Gaviria y Zapatero, 1880 (segunda edición: Valladolid, Imprenta, Litografía y Estéreo-Galvanoplastia de Gaviria, 1882).

Delgado Criado, Buenaventura (Coord.): Historia de la educación en España y América, Madrid, SM - Ediciones Morata, 1994, 3 vols.: La educación en la España contemporánea (1789-1975), vol. III.

Delon, Michel: "Procès de la rhétorique, triomphe de l'éloquence (1775-1800), en Fumaroli, Marc: Histoire de la rhétorique dans l'Europe moderne (1450-1950), Paris, Presses Universitaires de France, 1999, pp. 1001-1017.

Díaz Alcaraz, Francisco y Moratalla Isasi, Silvia: «La segunda enseñanza hasta la dictadura de Primo de Rivera», Ensayos, 28 (2008), pp. 255-282.

Dios Martín, José de: «Una contribución a la enseñanza secundaria de carácter privado en Sevilla: el Plan de Educación y Enseñanza de D. Francisco Luis Zapata (1815)», Cuestiones pedagógicas. Revista de Ciencias de la Educación, 4-5 (1987-1988), pp. 187-200.

Feijoo, Benito Jerónimo: Cartas eruditas y curiosas, en que, por la mayor parte, se continúa el designio del Teatro Crítico Universal, impugnando, o reduciendo a dudosas, varias opiniones comunes, Madrid, Imprenta Real de la Gaceta, 1742-1760.

Fernández López, Jorge: "La retórica en España en el siglo XIX: panorama y bibliografía", en Retórica e historia en el siglo XIX. Sagasta: oratoria y opinión pública (J. A. Caballero López, editor), Logroño, IER-Ayuntamiento de Calahorra, 2008, pp. 37-109.

Galino, María Ángeles: Historia de la educación, Madrid, Gredos, 1968, 3 vols.

García Tejera, María del Carmen: Conceptos y teorías literarias españolas del siglo XIX: Alberto Lista. Cádiz, Servicio de Publicaciones-Universidad de Cádiz, 1989.

«Presencia de las corrientes europeas de pensamiento en las poéticas y retóricas españolas del siglo xix», en Actas del III Simposio Internacional de la Asociación Española de Semiótica, celebrado en Madrid, durante los días 5, 6 y 7 de diciembre de 1988 (Retórica y lenguajes), Madrid, UNED, 1990, vol. I, pp. 449-457.

"La Retórica en el siglo xix", en Retórica, Texto, Comunicación, Cádiz, Universidad de Cádiz, 1994, vol. I, pp. 277-284.

Gil de Zárate, Antonio: De la instrucción pública en España, Madrid, Imp. del Colegio de Sordomudos, 1855, 3 vols.

Manual de Literatura. Principios Generales de Poética y Retórica. Parte primera, Madrid, Imprenta y librería de D. Ignacio Boix, 1844.

Resúmen Histórico de la Literatura Española. Segunda parte del Manual de Literatura (sexta edición corregida y aumentada), Madrid, Imprenta de Gaspar y Roig, Editores, 1874. 
González Alcázar, Felipe: "Sistematización y utilidad pedagógica de los géneros literarios: la asimilación de la tríada hegeliana en la preceptiva española del siglo XIX", Castilla, 28-29 (2003-2004), pp. 111-130.

Procesos de la poética clasicista: los tratados de preceptiva españoles del siglo XIX, Murcia, Universidad de Murcia, 2005.

Hernández Guerrero, José Antonio: «Supuestos epistemológicos de las Retóricas y Poéticas españolas del siglo XIX», Actas del III Simposio Internacional de la Asociación Española de Semiótica, celebrado en Madrid, durante los días 5, 6 y 7 de diciembre de 1988 (Retórica y lenguajes), Madrid, UNED, 1990, vol. I, pp. 537-544.

Kennedy, George A.: La retórica clásica y su tradición cristiana y secular. Desde la antigüedad hasta nuestros días, Logroño, Instituto de Estudios Riojanos - Ayuntamiento de Calahorra, 2003.

Krause, C. Christian Friedrich: Ideal de la humanidad para la vida, con introducción y comentarios por D. Julián Sanz del Río, Madrid, Imprenta de Manuel Galiano, 1860.

Lida, Clara E. y Zavala, Iris: La Revolución de 1868. Historia, pensamiento, literatura, Nueva York, Las Américas, 1970.

López Eire, Antonio: Retórica clásica y teoría literaria moderna, Madrid, Arco/Libros, 1997.

"La retórica clásica y la actualidad de la retórica", en Albaladejo Mayordomo, T.; Del Río Sanz, E. y Caballero López, J. A. (eds.): Quintiliano: Historia y Actualidad de la Retórica, Logroño, Instituto de Estudios Riojanos, 1998, vol. I, pp. 203-315.

Esencia y objeto de la retórica, Salamanca, Universidad de Salamanca, 2000.

Lozano, Claudio: La educación en los siglos XIX y XX, Madrid, Editorial Síntesis, 1994.

Mainer, José Carlos: Historia, literatura, sociedad (y una coda española, Madrid, Biblioteca Nueva, 2000.

Martínez Ezquerro, Aurora: "La educación lingüística y literaria a la luz de la Constitución de 1812: antecedentes y legislación posterior", en Aportaciones del constitucionalismo español a la educación lingüística y literaria (1812-2012), L. P. Cancelas y Ouviña y M. F. Romero Oliva (Coords.), Granada, Grupo Editorial Universitario - Fundación Biblioteca Virtual Miguel de Cervantes, 2013, pp. 9-28.

"Preceptiva literaria en el siglo XIX. Hipólito Casas y Gómez de Andino", en La educación en el valle del Ebro: estudios históricos y filológicos, A. Martínez Ezquerro e I. Martínez Navas (eds.), Logroño, Instituto de Estudios Riojanos, 2014, pp. 197-212.

Messer, August: Historia de la pedagogía, Madrid, Labor, 1927.

Ministerio de Educación y Ciencia: Historia de la educación en España, Madrid, MEC-Secretaría General Técnica, 1985, 3 vols.: De las Cortes de Cádiz a la Revolución de 1868, vol. II; y De la Restauración a la II República, vol. III.

Morales Sánchez, Isabel: "Los manuales de retórica y poética: un espacio de discusión sobre los géneros literarios en la primera mitad del siglo XIX", Cuadernos de ilustración y romanticismo, 8 (2000), pp. 167-175.

Mortara Garavelli, Bice: Manual de Retórica, Madrid, Cátedra, 1991.

Núñez Ruiz, Gabriel y Campos Fernández-Fígares, María del Mar: Cómo nos enseñaron a leer: manuales de literatura en España: 1850-1960, Toledo, Akal, 2005.

"Las historias de la literatura y la canonización de autores y obras en el sistema educativo español", Revista de Literatura, 151 (2014), pp. 39-55.

Historia de la educación lingüística y literaria, Madrid, Marcial Pons, 2016.

Pedrazuela, Mario: "La enseñanza de la lengua y la literatura en los institutos del siglo XIX. De la formación de retóricos y latinos a educar la imaginación”, BRAE, XCI (2001), pp. 325-351. 
Puelles Benítez, Manuel de: Educación e ideología en la España contemporánea (17671979), Barcelona, Labor, 1980.

Real Academia de la Historia. Fondo Vargas y Ponce, leg. XIII, "Informe a la Junta de Instrucción Pública", Gaceta de Madrid, 33, 2-2-1811.

Rincón, Francisco: "La lengua y la literatura en la enseñanza secundaria", Revista Interuniversitaria de Formación del Profesorado, 18 (1993), pp. 141-153.

Romero Tobar, Leonardo: La literatura en su historia, Madrid, Arco/Libros, 2006.

Soria Olmedo, Andrés: «Notas sobre Hugo Blair y la retórica española en el siglo xix», en Estudios sobre la literatura y arte: dedicados al profesor Emilio Orozco Díaz, ed. N. Marín, A. Gallego y A. Soria, Granada, Universidad de Granada, 1979, vol. 3, págs. 363-388.

Utande Igualada, Manuel: Planes de estudio de enseñanza media (1787-1963), Madrid, Dirección General de Enseñanza Media, 1964.

“Un siglo y medio de segunda enseñanza (1820-1970)", Revista de Educación, 271 (1982), pp. 7-41.

Viñao Frago, Antonio: Política y educación en los orígenes de la España contemporánea, Madrid, Siglo XXI, 1982.

VV. AA.: Diccionario biobliográfico de autores riojanos (C-E), Logroño, Instituto de Estudios Riojanos, 1995.

Walde, Lillian von der: "La posición ideológica de Manuel José Quintana en “A España, después de la revolución de marzo"", en Lecturas y relecturas de textos españoles, latinoamericanos y US latinos, vol. V de Actas Irvine-92. Asociación Internacional de Hispanistas, Ed. de Juan Villegas, Irvine, The Regents of the University of California, 1994, pp. 235-244.

Wellek, René: Historia de la crítica moderna (1750-1950), Madrid, Gredos, 1972. 